H. Wu, M. Tan, W. Zhu* and Z. S. Ma*

\title{
The Interaction between Erosion Particle and Gas Stream in High Temperature Gas Burner Rig for Thermal Barrier Coatings
}

https://doi.org/10.1515/htmp-2017-0172

Received November 18, 2017; accepted May 22, 2018

\begin{abstract}
Thermal barrier coatings (TBCs) as a kind of temperature-resistance materials have been widely applied in super high temperature components in aircraft engines. However, TBCs are subjected to harsh service environment such as high temperature oxidation and erosion, which lead to the coating failure. It is important to investigate the effect of fire temperature, angle and velocity of particle on erosion to understand the failure mechanism. In this paper, the temperature and velocity distributions of erosion particles in high temperature gas burner rig are investigated by using the fluid-solid coupling method with the discrete random walk model. The results show that a non-uniform distribution of temperature appears in different positions of the central axis, and the temperature of particle is affected obviously by the gas stream and particle size. The trajectory of particles and velocity diagrams under different particle size are determined by coupling the continuous phase with the erosion particles.
\end{abstract}

Keywords: thermal barrier coatings, erosion, numerical simulation, conjugated heat transfer, fluid-solid coupling

\section{Introduction}

The high inlet temperature is a key character of advanced aircraft engines whose performances are determined by the thermal insulation protection technology of hot components. Monocrystalline materials, film cooling and thermal barrier coatings (TBCs) are regarded as the three

*Corresponding authors: W. Zhu, Z. S. Ma, Key Laboratory of Low Dimensional Materials and Application Technology of Ministry of Education, School of Materials Science and Engineering,

Xiangtan University, Xiangtan 411105, China,

E-mail:wzhu@xtu.edu.cn; zsma@xtu.edu.cn

H. Wu: E-mail: 1304287623@qq.com, M. Tan:

E-mail: 1791637500@qq.com, Key Laboratory of Low Dimensional Materials and Application Technology of Ministry of Education, School of Materials Science and Engineering, Xiangtan University, Xiangtan 411105, China thermal insulation protection technologies. However, monocrystalline materials and film cooling almost have reached their technology limitations. Further increases in the thermal efficiency, thrust-to-weight ratio and durability of aircraft engines will rely on further improvement in TBCs [1]. Geometric structures of TBCs include three layers: a thermal-resistant ceramic coating (TC), an adhesionenhanced bond coating (BC) and a mechanical-withstand superalloy substrate. Though TBCs can sharply increase the service temperature of superalloy substrate, coating spallation is always the bottleneck of TBCs. On the one hand, huge residual stress arises in TBCs during a longtime exposure in service environment due to huge differences between their thermal and mechanical properties. On the other hand, TBCs usually withstand the harsh environment, which includes high temperature, thermal shock, oxidation, erosion and $\mathrm{CaO}-\mathrm{MgO}-\mathrm{Al}_{2} \mathrm{O}_{3}-\mathrm{SiO}_{2}$ (CMAS) corrosion [2-5], which may lead to cracking and spallation. Interfacial oxidation is thermally grown oxide (TGO) formed between TC and BC due to diffusion and reaction of oxygen and metal aluminum during a longtime thermal exposure. CMAS corrosion is that, as the temperature is higher than $1250^{\circ} \mathrm{C}$, the CMAS depositions melt and penetrate into the TBCs. This penetration affects the microstructure, mechanical behavior and composition of coating and then induces the interfacial delamination of the coating from the substrate [6-10]. However, the complicated environment is very difficult to be simulated by the conventional experimental method, especially for thermal shock and high temperature erosion. Therefore, it is urgent to develop the service environment simulation system of TBCs to investigate the failure mechanism.

The simulations of thermal shock and high temperature erosion are realized by the special designed spray gun. For example, the burning gas (such as, $\mathrm{C}_{2} \mathrm{H}_{2}, \mathrm{CH}_{4}$ ) and combustion-supporting gas $\left(\mathrm{O}_{2}\right)$ are mixed in the combustion chamber, then the mixed gas are fired and sprayed on the TBCs surface by the spray gun. As the erosion particles are added through the spray gun, the particles accelerate with the high temperature flow and impact on the TBCs surface. This process is used for erosion simulation. The relevant erosion simulation systems 
were established to simulate the high temperature erosion environment. Such as, NASA developed the high velocity combustion device, whose velocity can reach Mach 0.31.0 [11]. Canada's National Research Council (NRC) built the dynamic simulation system (LCS-4C), which can simulate the process of thermal shock and erosion [12, 13]. The high temperature tunnel equipment was established by German's Helmut Schmidt University. The high temperature erosion with different erosion angle and velocity can be simulated in virtue of this equipment [14]. It can be seen that it is the main simulation process of service that the high temperature flow carry the particles to accelerate and spray on a specimen. Therefore, in order to understand the failure mechanism of erosion, it is important to investigate the effect of fire temperature, angle and velocity of particles on erosion.

In the experiment, the fire temperature can usually be obtained by the thermocouple. By tracking the particle trajectory, the particle velocity can be gotten using the high speed camera [13-20]. However, the above methods are only suitable for the measurement of local region temperature and velocity. Furthermore, it is difficult to investigate the interaction between fire and particles. Numerical simulations have been an attractive tool to understand the mechanisms of the distributions of temperature and velocity of gas stream and particle as well as erosion process of TBCs. Based on the numerical simulations, the distributions of temperature and velocity of gas stream and particle as well as the process of thermal shock and erosion can be obtained. Zhu et al. [11] have investigated the erosion mechanisms based on the newly established erosion burner rig testing in simulated sand ingestion environments. Also, in order to optimize our own spray gun rig of thermal shock and high temperature erosion, it is urgent to establish a solid-fluid two-phase model to investigate the complex interaction between erosion particle and gas stream in it.

In this work, a finite element model of a spray gun used for high temperature erosion is built up to investigate the distributions of temperature and velocity of gas stream and particle. Firstly, the $k-\varepsilon$ turbulence model is used to investigate the distributions of temperature and velocity field of high temperature gas stream in the condition of different Mach number. Thereafter, the motion characteristics of the erosion particles from the gas stream are simulated based on the discrete random walk model. The temperature distributions of gas stream and erosion particle are obtained. Finally, the effects of different Mach number and particle diameter on the velocity and temperature fields are discussed, which lay the foundation for the design of spray gun.

\section{Procedure description}

\section{The fluid model}

In the flow field, the pressure and velocity are intercoupling. For a two-dimensional steady state coupling, the solution of pressure and velocity are governed by compressible flow Navier-Stokes equations [21]

$$
\frac{D\left(\rho_{\mathrm{f}} \boldsymbol{v}\right)}{D t}=-\operatorname{grad} p+\operatorname{div}\left(\mu_{\mathrm{f}} \operatorname{grad} \boldsymbol{v}\right)+\boldsymbol{S}_{\mathrm{M}}
$$

where the $\rho_{\mathrm{f}}$ and $\mu_{\mathrm{f}}$ are density and dynamic viscosity of fluid, respectively. $\boldsymbol{p}$ is pressure, $\boldsymbol{v}$ is the velocity vector, and $\boldsymbol{S}_{\mathrm{M}}$ is the source item of momentum conservation equation.

Due to the violent heat transfer of high temperature erosion, energy conservation must be satisfied, which is governed by energy conservation law [22]

$$
\frac{\partial\left(\rho_{\mathrm{f}} T_{\mathrm{f}}\right)}{\partial t}+\operatorname{div}\left(\rho_{\mathrm{f}} v T_{\mathrm{f}}\right)=\operatorname{div}\left(\frac{k_{\mathrm{f}}}{c_{p}} \operatorname{grad} T_{\mathrm{f}}\right)+S_{\phi}
$$

where $c_{p}$ is the specific heat of fluid, $T_{\mathrm{f}}$ is the temperature of flow field and $S_{\phi}$ is the source item of energy equation.

Owing to the high Reynolds number and thin viscosity, the combusting gas can be assumed to be ideal gas in combustion chamber, which has been accepted by many researchers of this field. The equations of state are followed by

$$
\left\{\begin{array}{l}
p=R \rho_{\mathrm{f}} T_{\mathrm{f}} \\
e_{\mathrm{f}}=c_{p} T_{\mathrm{f}}
\end{array}\right.
$$

where $R$ and $e_{\mathrm{f}}$ are the ideal gas constant and internal energy.

According to mass, momentum, energy conservation equations and the equations of state, fundamental physics parameters of flow field including velocity $v_{\mathrm{i}}$, temperature $T_{\mathrm{f}}$ and pressure $p$ can be obtained [23, 24]. In the flow field, the Reynolds number is in the range of $10,000-20,000$, the realizable $k-\varepsilon$ turbulence model is selected to describe the turbulent flow.

\section{The particle model}

\section{Particle dynamic model}

Assuming that the force imposed on the particle is linear, the acting force on the particle includes the drag force due to the velocity difference between the particle and the gas stream, force owing to temperature and pressure 
gradients [24-31]. The equation of motion for particles can be obtained from the Newton's second law

$$
\sum \boldsymbol{F}=m \frac{d \boldsymbol{u}_{p}}{d_{t}}
$$

where $\boldsymbol{F}$ is the acting force imposed on the particle, of which the drag force plays the leading role. Therefore, only the drag force is considered in this work for the sake of simplification, which is described by [24]

$$
\boldsymbol{F}_{D}=\frac{1}{2} \rho_{g} C_{D} S\left|\boldsymbol{u}_{g}-\boldsymbol{u}_{p}\right|\left(\boldsymbol{u}_{g}-\boldsymbol{u}_{p}\right)
$$

where $\rho_{\mathrm{g}}$ is the gas density, $S$ is the effective loading area of particles. $\boldsymbol{u}_{\mathrm{g}}$ and $\boldsymbol{u}_{\mathrm{p}}$ are gas and particle velocity, respectively. $C_{D}$ is a drag coefficient, which is specified by $[24,32]$

$$
\begin{gathered}
C_{D}=\frac{24}{\operatorname{Re}}\left(1+0.15 \operatorname{Re} d^{0.687}\right) \\
\operatorname{Re}=\frac{\rho_{\mathrm{g}} d\left|\boldsymbol{u}_{\mathrm{g}}-\boldsymbol{u}_{\mathrm{p}}\right|}{\mu_{\mathrm{g}}}
\end{gathered}
$$

where $R e$ is the Reynolds number based on particle diameter, $d$ is the particle diameter and $\mu_{\mathrm{g}}$ is gas viscosity.

Then, the equation of motion for particles can be rewritten as

$\frac{d \boldsymbol{u}_{p}}{d_{t}}=\frac{\boldsymbol{F}_{D}}{m_{p}}=\frac{18 \rho g}{\operatorname{Re} d_{p} p_{p}}\left(1+0.15 \operatorname{Re} d^{0.687}\right)\left|\boldsymbol{u}_{g}-\boldsymbol{u}_{p}\right|\left(\boldsymbol{u}_{g}-\boldsymbol{u}_{p}\right)$

\section{Discrete random walk model}

As mentioned, the Reynolds number is in the range of $10,000-20,000$ in the flow field, while the particle is driven by the gas flow. Therefore, to ascertain the motion of particle obey the characteristic distribution and extent of turbulence. The equation of motion for particles considering the effect of turbulence is described by the discrete random walk model (DPM), which discrete the variation of velocity with the fluctuation of the turbulent flow as a function of time.

Assuming that the force imposed on the particle is linear, the particle locus equation is specified by

$$
\frac{d \boldsymbol{x}}{d t}=\boldsymbol{u}_{P}
$$

Due to the velocity difference between particle and gas stream, the equation of motion for particles can be simplified as

$$
\frac{d u_{p}}{d t}=\frac{\boldsymbol{u}_{g}-\boldsymbol{u}_{p}}{\tau_{p}}
$$

where $\tau_{\mathrm{p}}$ is the relaxation time of particle. The discretization form of eq. (10) is

$$
\begin{gathered}
\frac{\boldsymbol{u}_{\mathrm{p}}{ }^{\mathrm{n}+1}-\boldsymbol{u}_{\mathrm{p}}{ }^{n}}{\Delta t}=\frac{1}{\tau}\left(\boldsymbol{u}^{\star}-\boldsymbol{u}_{\mathrm{p}}{ }^{\mathrm{n}+1}\right)+\ldots \\
\boldsymbol{u}^{\star}=\frac{1}{2}\left(\boldsymbol{u}^{n}+\boldsymbol{u}^{n+1}\right) \\
\boldsymbol{u}^{\boldsymbol{n}+1}=\boldsymbol{u}^{\boldsymbol{n}}+\boldsymbol{u}_{\mathrm{p}}{ }^{n} \cdot \Delta t \cdot \nabla \boldsymbol{u}^{\boldsymbol{n}}
\end{gathered}
$$

Based on the finite difference method, the discrete eq. (11) is solved by using eqs. (12) and (13) for a given time. The approximate solution of velocity and location for particle can be obtained.

\section{Conjugate heat transfer}

During the high temperature erosion, there is heat transfer occurring between the gas flow and particle. It is worth noting the following assumptions are introduced: (1) The system is an energy conservation system; (2) The above process satisfies the law of mass conservation; (3) Only the thermal convection is considered between the gas-solid two-phase flow, and the thermal radiation is not taken into account.

Due to radiation from the surroundings to particles is negligible, which compared to the convective heat flux between the gas flow and the particle, therefore, the particle is treated as isothermal. The heating rate is described by [33]

$$
\frac{d T_{\mathrm{P}}}{d t}=\frac{6 h}{C_{p-p} \rho_{\mathrm{p}} d_{\mathrm{p}}}\left(T_{\mathrm{f}}-T_{\mathrm{p}}\right)
$$

where $T_{\mathrm{f}}$ and $T_{\mathrm{p}}$ are the temperature of gas flow and particle, respectively. $h$ is the convection coefficient, which is described by Nusselt number [34]

$$
h=\frac{\lambda_{g} N u}{d_{\mathrm{p}}}
$$

Nusselt number is specified by

$$
N u=2+0.6 \operatorname{Re}^{0.5} \operatorname{Pr}^{\frac{1}{3}}
$$

Prandtl number is given by [33] 


$$
\operatorname{Pr}=\frac{\mu_{g} C_{p-g}}{\lambda_{g}}
$$

where $\lambda_{\mathrm{g}}$ is the thermal conductivity of flow, the $C_{p-\mathrm{g}}$ is the specific heat capacity of the gas flow, and $\mu_{\mathrm{g}}$ is the coefficient of kinetic viscosity of the gas flow.

Substituting eqs. (15) - (17) into eq. (14), eq. (18) can be obtained:

$$
\frac{d T_{\mathrm{P}}}{d t}=\frac{6 \lambda_{g}\left(T_{\mathrm{f}}-T_{\mathrm{p}}\right)}{C_{p-\mathrm{p}} \rho_{p} d^{2} p}\left[2+0.6\left(\frac{\left(u_{g}-u_{p}\right)}{\mu_{g}}\right)^{\frac{1}{2}}\left(\frac{C_{p-g} \mu_{g}}{\lambda_{g}}\right)^{\frac{1}{3}}\right]
$$

For the above equation, the derivative of temperaturetime is transformed into the differential of the moving distance of the particle. Moreover, taking the absolute value of the velocity difference between the gas flow and the particle:

$\frac{d T_{\mathrm{P}}}{d t}=\frac{d T_{\mathrm{p}}}{d x} \frac{d x}{d t}=\frac{6 \lambda_{\mathrm{g}}\left(T_{\mathrm{f}}-T_{\mathrm{p}}\right)}{\mathrm{C}_{p-\mathrm{p}} \rho_{p} d^{2} p}\left[2+0.6\left(\frac{\left(u_{g}-u_{p}\right)}{\mu_{g}}\right)^{\frac{1}{2}}\left(\frac{C_{p-g} \mu_{g}}{\lambda_{g}}\right)^{\frac{1}{3}}\right] u_{p}$

It can be seen from the above equation, the temperature of particle is associated with its density, diameter, specific heat, density and specific heat of gas stream, the velocity difference of gas stream and particle. The smaller particles diameter, specific heat and density are, the faster heating in the field of gas stream. Based on the conjugate heat transfer analysis, the temperature field of particle is obtained by using the software of FLUENT.

\section{Model development}

\section{Geometric description}

A schematic representation of the spray gun is shown in Figure 1. The structure of spray gun consists of five parts: the intake system of fuel gas and combustion air, mixture chamber, combustion chamber, particles injection channel and the water-cooled system of Laval nozzle. The fuel gas and combustion air are premixed in the mixture chamber, then the mixed gas are fired in the combustion chamber. At the same time, erosion particles are injected through the channel. The high temperature gas stream and particles are accelerated by the Laval nozzle and sprayed out through the nozzle. The water-cooled system of Laval nozzle is running with the temperature of $10^{\circ} \mathrm{C}$ in order to prevent the nozzle overheating. Based on the structure of spray gun, the computational geometry model is established (see Figure 2). Taking symmetry into account, the two-dimensional axisymmetric finite element model is considered. All dimensions are in millimeters.

\section{Material property}

During the high temperature erosion, the particles carried by gas mixture include: $\mathrm{Al}_{2} \mathrm{O}_{3}, \mathrm{CaO}, \mathrm{MgO}$ and unburned carbon particles. In this work, the $\mathrm{CaO}$ particles are selected as the erosion particles. The detailed material properties of $\mathrm{CaO}$ are given in Table 1 . It should be noted that, some assumptions are adopted in the erosion process: (1) The collisions between particles are not taken into account; (2) There is no fracture occurs in the particle as the particle impact on the wall; (3) The volume of particles is neglible. The initialization parameters of particle are shown in Table 2.

\section{Meshing and boundary conditions}

The grid is generated by the GAMBIT of FLUENT. The structured quadrilateral grid is adopted to the model and the finite element model of the geometric which shows that the grid has 69,005 total nodes and 135,590 total cells in Figure 3. Finer grid is used around the drastic change zones (such as, the inlet of nozzle, outlet

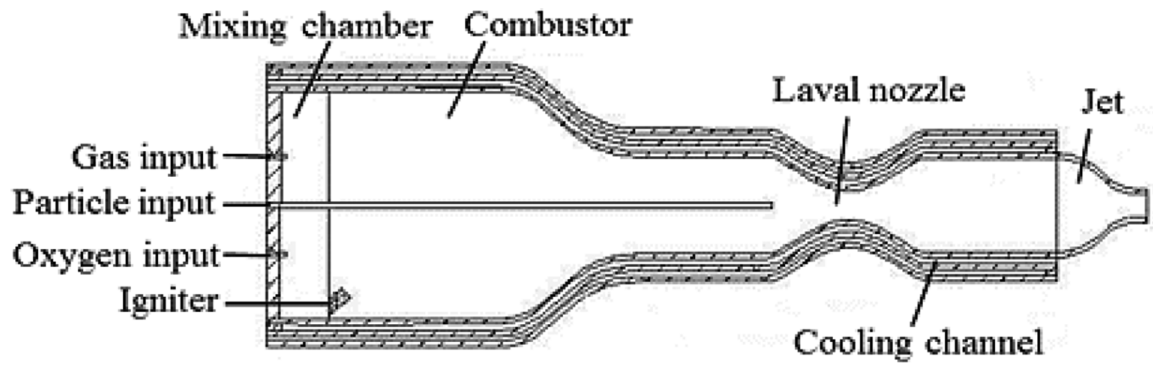

Figure 1: Schematic illustration of spraying gun. 


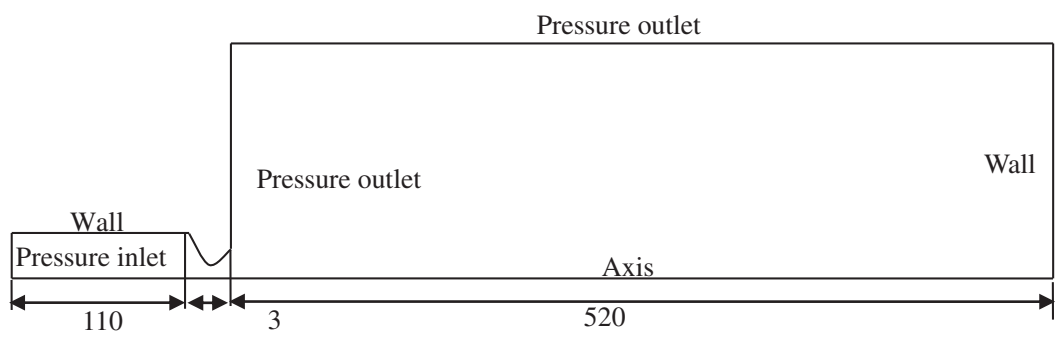

Figure 2: Geometry of computational region.

Table 1: Thermal properties of Cao.

\begin{tabular}{lrr}
\hline Density $\left(\mathrm{kg} / \mathrm{m}^{3}\right)$ & $\begin{array}{r}\text { Ratio of specific heat } \\
\text { capacities }(\mathrm{J} / \mathrm{kg} \cdot \mathrm{K})\end{array}$ & $\begin{array}{r}\text { Heat conductivity } \\
(\mathrm{W} / \mathrm{m} \cdot \mathrm{K})\end{array}$ \\
\hline
\end{tabular}

\begin{tabular}{lll}
\hline 3320 & 783 & 2.25 \\
\hline
\end{tabular}

Table 2: Initial parameters of particle.

\section{Initial conditions}

Injection type Diameter distribution X-Velocity $(\mathrm{m} / \mathrm{s})$ Y-Velocity $(\mathrm{m} / \mathrm{s})$ Diameter $(\mu \mathrm{m})$ Temperature (K) Mass flow rate $(\mathrm{kg} / \mathrm{s})$

and the central zone of jet flow) in the flow field to improve the accuracy of simulation results. There are four different types of boundary conditions: the inlet boundary, the outlet boundary, the solid wall boundary and the axisymmetric boundary. The total temperature
$\left(T_{\mathrm{t}, \text { inlet }}\right)$, total pressure $\left(P_{\mathrm{t}, \text { inlet }}\right)$ and static pressure $\left(P_{\mathrm{s}}\right.$, inlet) are fixed at the inlet boundary; the average staticpressure $\left(P_{\mathrm{s} \text {,outlet }}\right)$ is given at the outlet boundary; at the solid wall, the no-slip boundary condition is adopted. The detailed parameters of boundary conditions are presented in Table 3.

\section{Results and discussions}

\section{The evolution of temperature}

Figure 4 shows the contours of temperature distribution of gas stream in the inlet condition of Mach 0.3. It can be seen that the temperature of the gas stream falls drastically as the gas stream ejecting from the Laval nozzle. This is because that the intense interaction between high energy gas stream and air leads to the heat loss. Moreover, the more distant the gas stream far away from the spray gun, the lower the temperature value is. In addition, the temperature distributions of gas stream along the axial direction at different Mach number are given in Figure 5. It is found that the temperature of gas

(a)

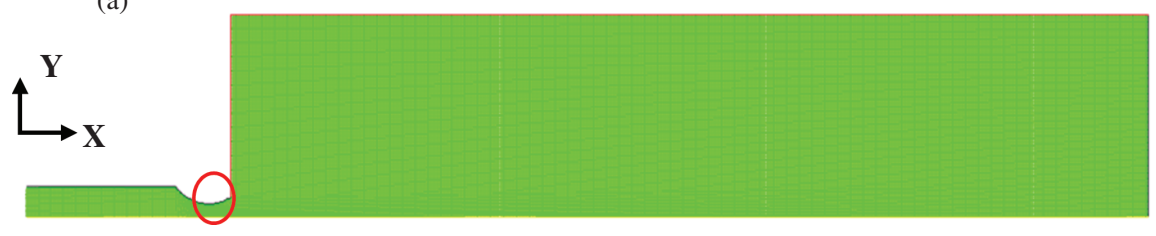

(b)

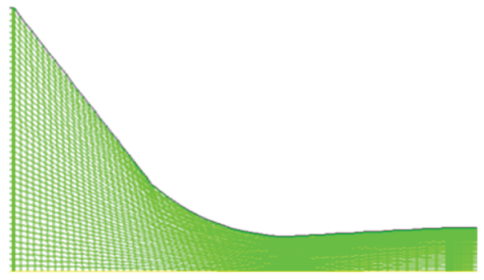

Figure 3: Grid of geometry region (a) grid of computational region (b) grid of the nozzle. 
Table 3: The detailed parameters of boundary conditions.

\begin{tabular}{lrrrrr}
\hline $\begin{array}{l}\text { Mach } \\
\text { numbers }\end{array}$ & $\begin{array}{r}\text { Total } \\
\text { temperature(K) }\end{array}$ & $\begin{array}{r}\text { Total pressure } \\
(\mathrm{MPa})\end{array}$ & $\begin{array}{r}\text { Static-pressure } \\
(\mathrm{MPa})\end{array}$ & $\begin{array}{r}\text { Average static- } \\
\text { pressure(Pa) }\end{array}$ & $\begin{array}{r}\text { Turbulence } \\
\text { intensity }\end{array}$ \\
\hline 0.3 & 1600 & 1.21 & 1.10 & $1.013 \times 10^{5}$ & $4.9 \%$ \\
0.5 & 1600 & 1.34 & 1.24 & $1.013 \times 10^{5}$ & $5.09 \%$ \\
0.9 & 1600 & 1.87 & 1.76 & $1.013 \times 10^{5}$ & $5.19 \%$ \\
\hline
\end{tabular}
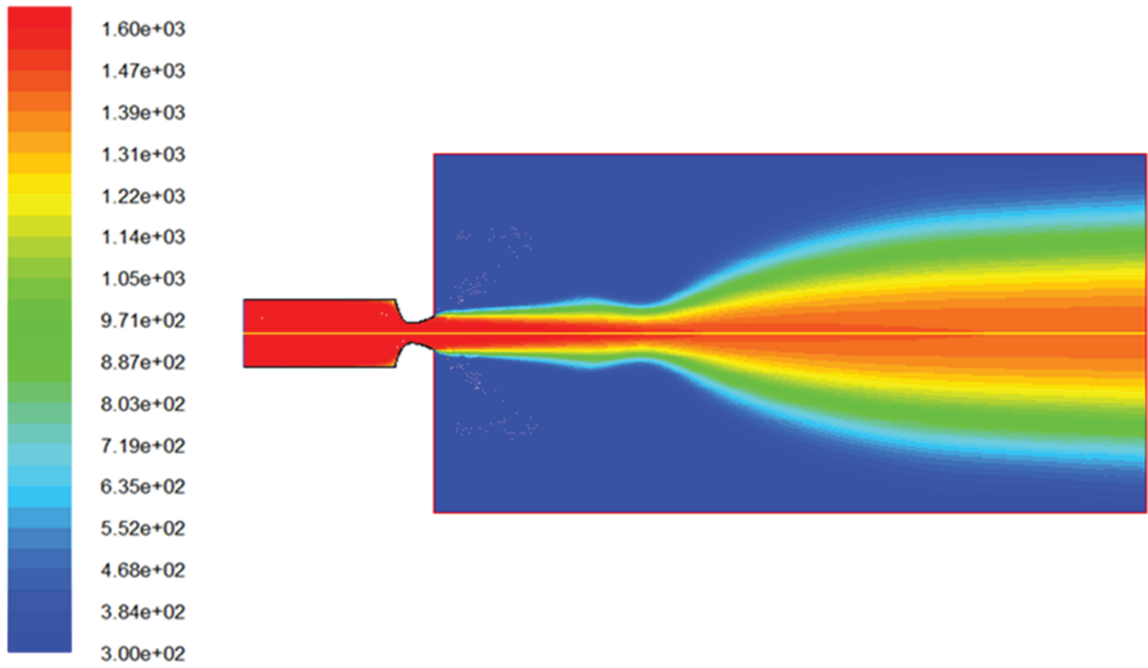

Figure 4: The contours of gas temperature at Mach 0.3.

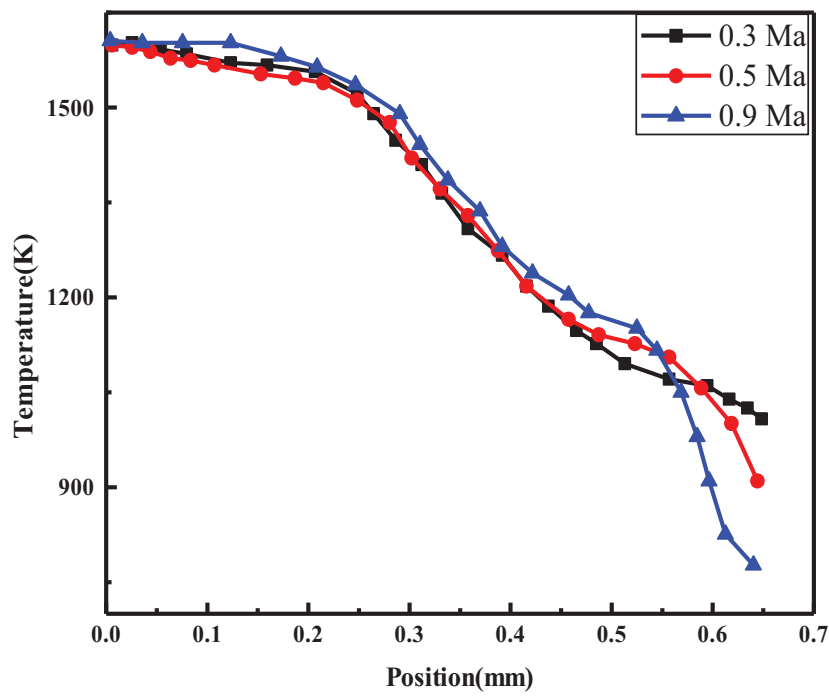

Figure 5: Gas temperature profiles from Mach 0.3 to Mach 0.9.

stream drops more quickly at the outlet of the nozzle with the increase of the Mach number. This is attributed to that the interaction between gas stream and air is more intense at the high Mach number, which results in much more energy loss.
Comparisons of temperature distribution of different particles along the axial direction in the condition of different Mach number are shown in Figure 6. The erosion particle is injected through the spray gun and heated by the gas stream. The temperature variation of particle is similar to that of gas stream. The temperature of particle follows that of gas stream temperature. However, due to the heat transfer delay between the high temperature gas stream and particle, the decrease of particle temperature does not synchronize with that of gas stream temperature. Furthermore, the particle temperature is even higher than that of the gas stream as the distance is far from the spray gun. For the case of Mach 0.3, the particle temperature follows the gas stream temperature as the particle size is small. The particle temperature rises and then drops quickly. The highest temperature of particle is approximately $1513 \mathrm{~K}$ as its size is $10 \mu \mathrm{m}$. With the increase of particle size, the heating rate of particle slows down. As the particle size reaches $75 \mu \mathrm{m}$, the highest temperature of particle is $820 \mathrm{~K}$. Furthermore, with the increase of particle size, there is an obvious asynchronism of temperature variation between the high temperature gas stream and particle. As the particle size is more than $50 \mu \mathrm{m}$, the particle temperature rises with the distance from the 

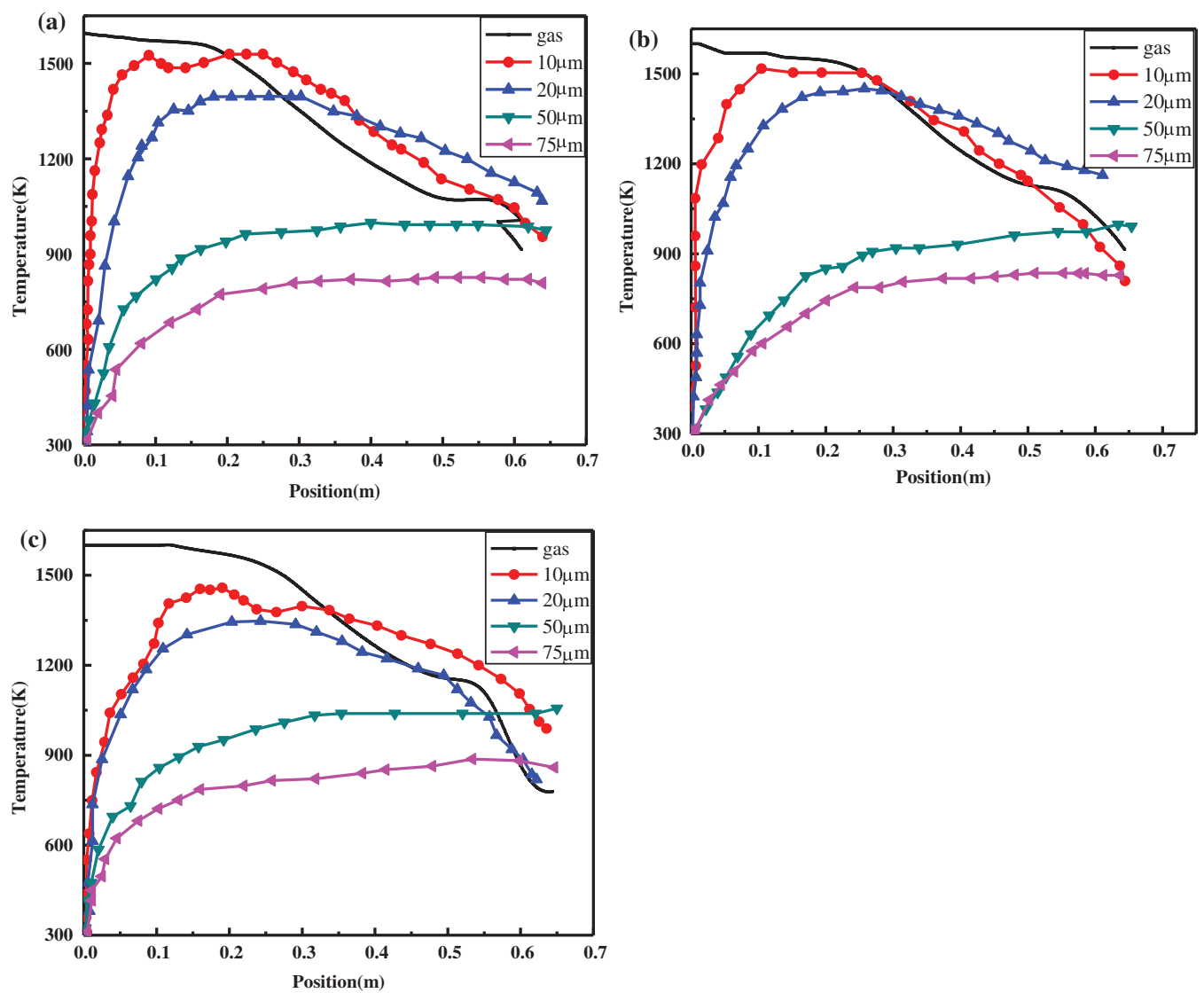

Figure 6: Gas temperature versus to particle temperature for different size particles at different Mach numbers: (a) Mach 0.3 , (b) Mach 0.5 and (c) Mach 0.9 .

spray gun, whereas the gas stream temperature drops when the distance is far from the spray gun. Temperature distribution of different particle size along the axial direction are almost is irrelevant to the Mach number. The effect of Mach number on the temperature distribution of different particle size can be neglected.

\section{The evolution of velocity}

The contours of velocity distribution of gas stream at Mach 0.3 is shown in Figure 7. As the gas stream passes through the Laval nozzle, the velocity of gas stream increases drastically and is up to its maximum caused by the special structural design of nozzle, then drops quickly from the nozzle. When the distance is far from the Laval nozzle, the velocity is rather minimal due to the energy dissipation of interaction between the gas stream and air flow. Velocity distribution of flow field along the axial direction is smooth, which is seen to be streamlined. Velocity distribution of gas stream along the axial direction at Mach 0.3, Mach 0.5 and Mach 0.9 are shown in Figure 8. It can be

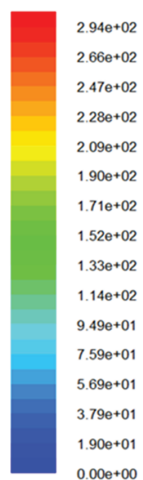

Figure 7: The contours of gas velocity at Mach 0.3 .

seen that the gas velocity distribution at different Mach number are similar but the magnitude are different. The difference in Mach numbers affects the magnitude of the initial velocity of gas stream. Owing to the acceleration effect of Laval nozzle, the gas stream velocity rises sharply. The larger the Mach numbers, the more obvious the acceleration effect is. As the Mach number is 0.3, the maximum gas stream velocity is $250 \mathrm{~m} / \mathrm{s}$. When the Mach number 


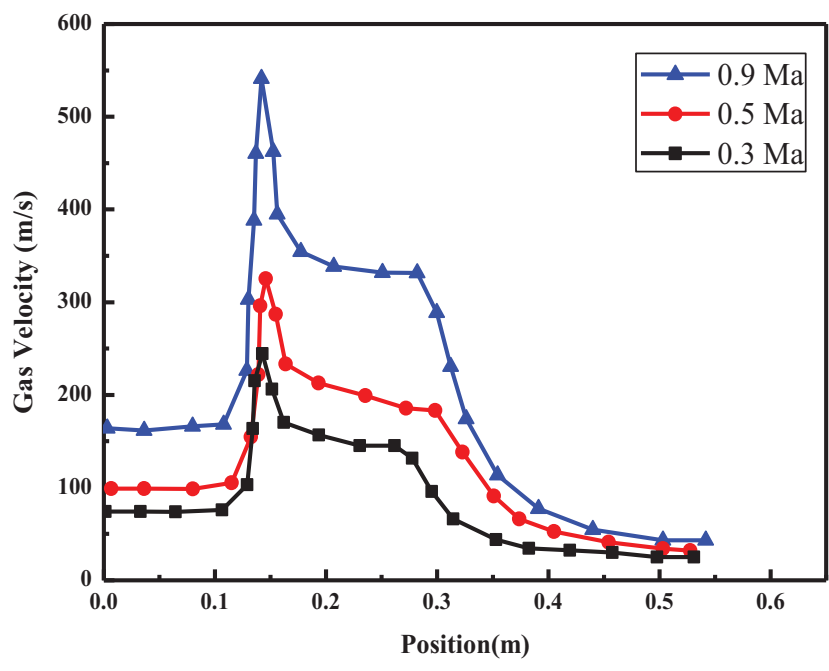

Figure 8: Plot of gas velocity at Mach 0.3-Mach 0.9.

reaches 0.9 , the gas stream velocity rises to $550 \mathrm{~m} / \mathrm{s}$. While as the distance is far away from the Laval nozzle, the gas stream falls quickly with the increase of Mach number. Finally, when the distance far from the Laval nozzle reaches $0.52 \mathrm{~m}$, the gas stream velocity are all close to zero.

Based on the simulation of the coupled interaction between the gas stream and the particle, velocity distributions of gas stream and particle along the axial direction at Mach 0.3, Mach 0.5 and Mach 0.9 can be obtained (see Figure 9). The erosion particles are added through the spray gun and accelerated by the gas stream due to the momentum transfer, then the mixture of gas and particle are injected by the spray gun. The velocity has two features: (1) The velocity of gas stream is larger than that of the velocity of particle before the mixture of gas and particle are injected by the spray gun. As the distance is far away from the Laval nozzle, the particle velocity is even larger than that of gas stream. This phenomenon is much more obvious with increasing of the Mach number; (2) The accelerated velocity rises with the increase of the Mach number and the acceleration distance of particles is longer. This is associated with the results of the force imposed on the particle. Furthermore, the smaller the particle size, the larger the accelerated velocity is.
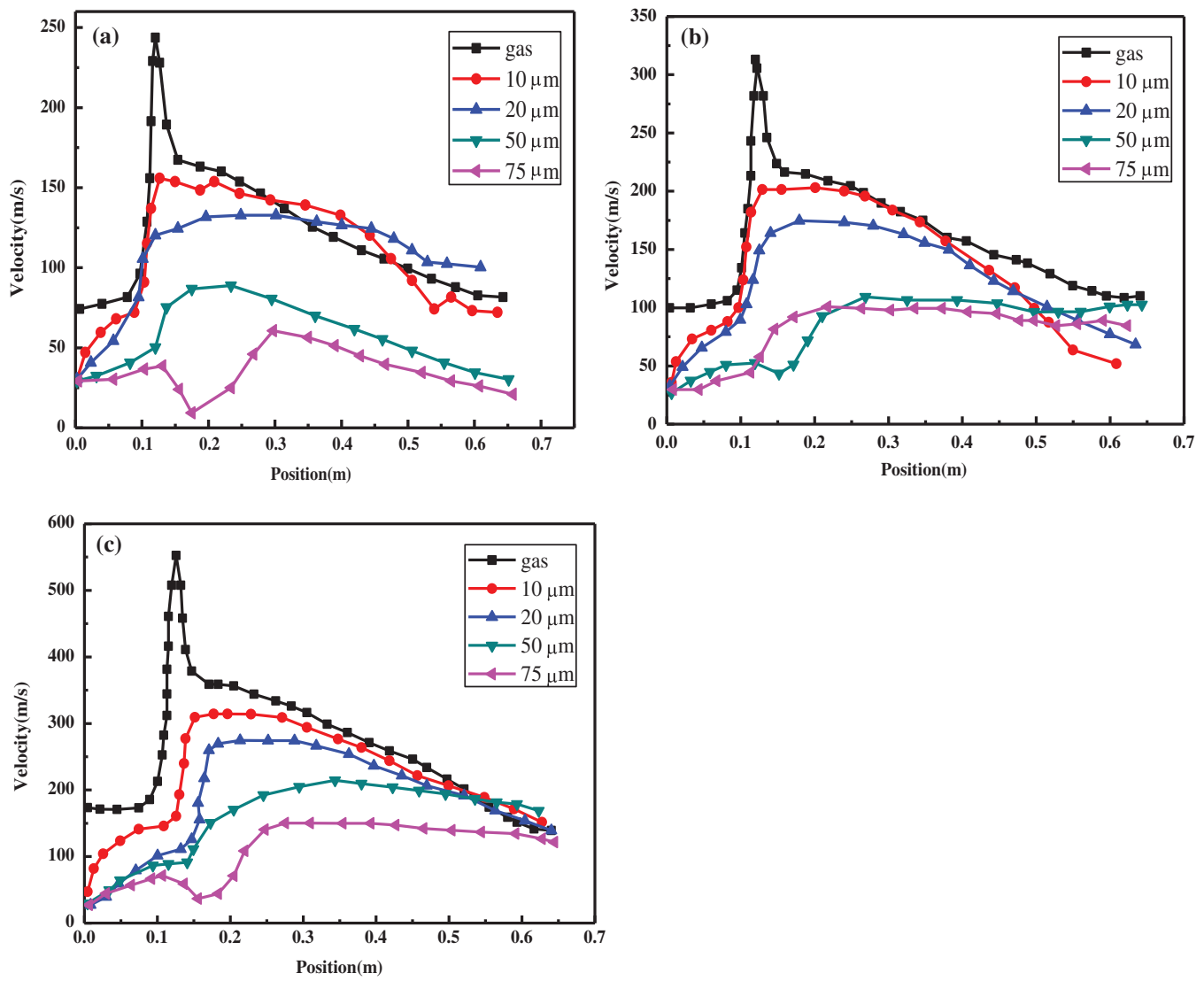

Figure 9: Gas velocity versus to particle velocity for different size particles at different Mach numbers: (a) Mach 0.3 , (b) Mach 0.5 and (c) Mach 0.9. 
The contours of velocity distribution of particle are shown in Figure 10. It shows that as the distance from the Laval nozzle reach 50 and $110 \mu \mathrm{m}$, the particle velocity are $148 \mathrm{~m} / \mathrm{s}$ and $153 \mathrm{~m} / \mathrm{s}$ at Mach $0.3,198 \mathrm{~m} / \mathrm{s}$ and $212 \mathrm{~m} / \mathrm{s}$ at Mach 0.5, respectively. The simulations of particle velocity are compared with that obtained by the erosion experiment. It is found that the simulation results are comparable to the experimental values (see Figure 11), which confirms the validity of this simulation.

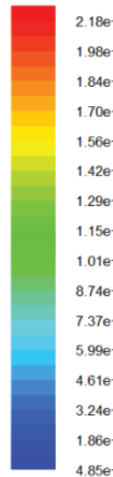

(a)

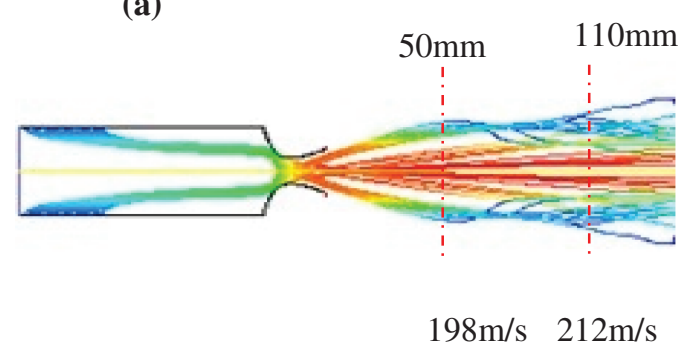

(b)

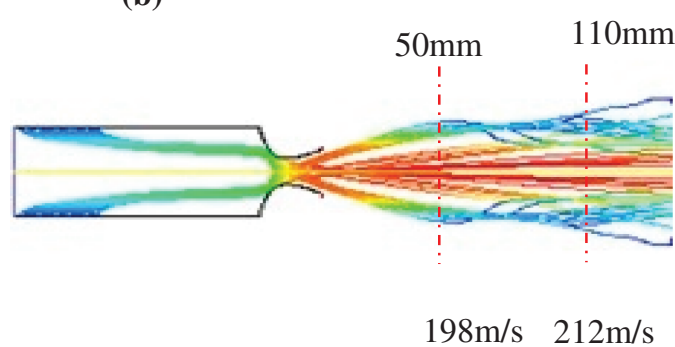

Figure 10: 10 um particle distribution of velocity at different Mach number: (a) Mach 0.3 and (b) Mach 0.5 .

\section{Conclusions}

A 2D numerical model of burner has been developed to investigate the temperature and velocity distribution regularities by a fluid-solid coupling method. A reasonable turbulence model (realizable $k-\varepsilon$ ) has been selected to describe the internal flow field. Based on the finite volume method, the evolution of temperature and velocity distribution have been obtained by solving the equations (such as, N-S, the fluid-solid coupled dynamics, conjugate heat transfer). The main conclusions include:
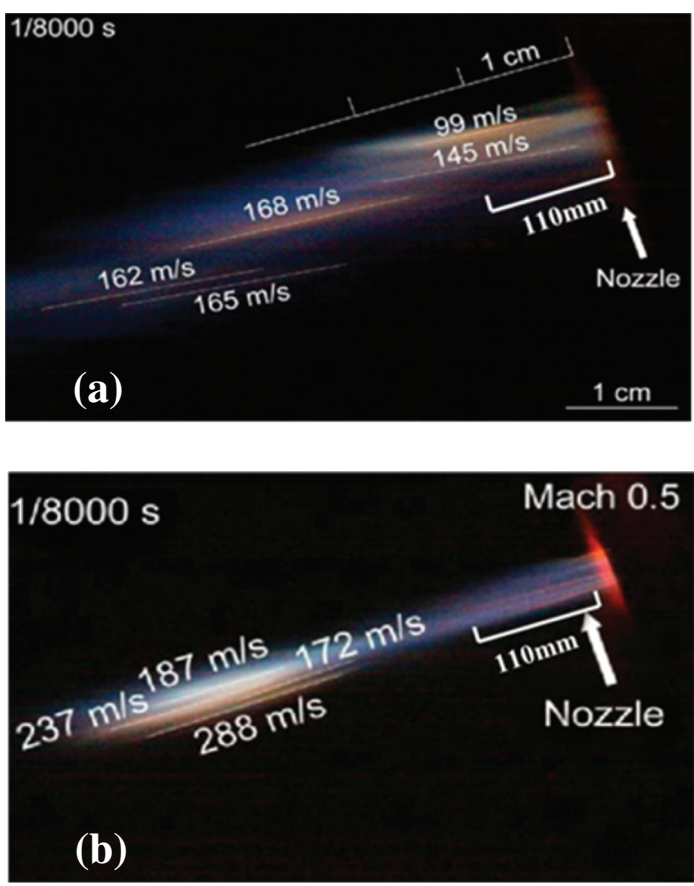

Figure 11: Representative photograph of the particle velocity (a) Mach 0.3 and (b) Mach 0.5 [11].

(1) A non-uniform distribution of temperature appears in different positions of the central axis. There is about 600 to $800 \mathrm{~K}$ for temperature difference of gas stream between the entrance and distal jet at Mach 0.3-Mach 0.5 , which revealed that the temperature fall along the central axis, especially falling with the increases of Mach number. Also particles temperature is affected obviously by the gas stream and particle size.

(2) Due to the special mechanical structure of Laval nozzle, the velocity of gas stream has a surge in the throat of nozzle. Moreover, the maximum of velocity increase with the increase of Mach number. The velocity is trend to a approximated value in the distal end. Also, the velocity of particles is affected obviously by the gas stream and their own particle size.

(3) The simulation results reveal the variations of velocity and temperature of gas stream and particle under the erosion process, and provide a theoretical guidance for the subsequent gun design and feed of simulation experiment.

Acknowledgements: This work was supported by the National Natural Science Foundationof China (grant No. 11602211), the Hunan Provincial Natural Science Foundation of China (Grant No. 2017JJ3307), and the Outstanding Youth Foundation of Hunan Provincial Education Department (Grant No. 16B249). 


\section{References}

[1] N.P. Padture, M. Gell and E.H. Jordan, Science, 296 (2002) 280-284.

[2] W. Lih, E. Chang, B. Wu and C. Chao, Oxid Met., 36 (1991) 221-238.

[3] R.A. Miller, J. Therm. Spray Technol., 6 (1997) 35-42.

[4] L. Yang, Y. Zhou, W. Mao and Q. Liu, Surf. Rev. Lett., 14 (2007) 935-943.

[5] L. Yang, Y. Zhou and C. Lu, Acta Mater., 59 (2011) 6519-6529.

[6] D. Clarke and C. Levi, Annu Rev Mater Res., 33 (2003) 383-417.

[7] A.G. Evans, D.R. Clarke and C.G. Levi, J. Eur. Ceram. Soc., 28 (2008) 1405-1419.

[8] A. Rabiei and A. Evans, Acta Mater., 48 (2000) 3963-3976.

[9] R.A. Miller, Surf. Coat. Technol., 30 (1987) 1-11.

[10] J. Aktaa, K. Sfar and D. Munz, Acta Mater., 53 (2005) 4399-4413.

[11] D. Zhu, R.A. Miller and M.A. Kuczmarski, NASA/TM-2010215669, 2010.

[12] R. Vaßen, F. Cernuschi, G. Rizzi, A. Scrivani, N. Markocsan, L. Östergren, A. Kloosterman, R. Mevrel, J. Feist and J. Nicholls, Adv. Eng. Mater., 10 (2008) 907-921.

[13] R. Wanhill, A. Mom, H. Hersbach, G. Kool and J. Boogers, Natl. Lucht Ruimtevaartlab. Rep., 7 (1989) 202-211.

[14] M. Kirschner, T. Wobst, B. Rittmeister and C. Mundt, J. Eng. Gas Turbines Power., 137 (2015) 032101.

[15] R.A. Miller and M.A. Kuczmarski, J. Test. Eval., 42 (2014) 648-658.

[16] A. Evans, N. Fleck, S. Faulhaber, N. Vermaak, M. Maloney and R. Darolia, Wear, 260 (2006) 886-894.

[17] D. Cheng, Q. Xu, E. Lavernia and G. Trapaga, Metall Mater Trans B., 32 (2001) 525-535.
[18] S. Kamnis, S. Gu and N. Zeoli, Surf. Coat. Technol., 202 (2008) 2715-2724.

[19] S. Kamnis and S. Gu, Chem. Eng. Sci., 61 (2006) 5427-5439.

[20] R.A. Miller, M.A. Kuczmarski and D. Zhu, NASA/TM-2011217008, 2011.

[21] R. Eymard, T. Gallouët and R. Herbin, Handb.Numer.Anal., 7 (2000) 713-1018.

[22] L. Hylton, M. Mihelc, E. Turner, D. Nealy and R. York, NASA-CR-168015, 1983.

[23] D. Zhu and R.A. Miller, Int. J. Appl. Ceram. Technol., 1 (2004) 86-94.

[24] S. Gu and S. Kamnis, Surf. Coat. Technol., 203 (2009) 3485-3490.

[25] S. Kamnis, S. Gu, T. Lu and C. Chen, Comput. Mater. Sci., 43 (2008) 1172-1182.

[26] E. Walhorn, A. Kölke, B. Hübner and D. Dinkler, Comput Struct., 83 (2005) 2100-2111.

[27] S. Kamnis, S. Gu, T.J. Lu and C. Chen, Comput. Mater. Sci., 46 (2008) 1038-1043.

[28] N. Zeoli and S. Gu, Comput. Mater. Sci., 42 (2008) 245-258.

[29] M. Li and P.D. Christofides, Chem. Eng. Sci., 61 (2006) 6540-6552.

[30] B.A. Schrefler, P. Brunello, D. Gawin, C.E. Majorana and F. Pesavento, Comput. Mech., 29 (2002) 43-51.

[31] C.H. Zhang, Y. Liu, R.M.C. So and N. Phan-Thien, Comput. Mech., 29 (2002) 422-429.

[32] S.A.J. Morsi and A.J. Alexander, J. Fluid Mech., 55 (1972) 193-208.

[33] W.Y. Li and C.J. Li, J. Therm. Spray Technol., 14 (2005) 391-396.

[34] B. Xu and A. Yu, Chem. Eng. Sci., 52 (1997) 2785-2809. 